Paidéia, 2001, 11(20), 57-68

\title{
O PAPEL MASCULINO DOS ANOS QUARENTA AOS NOVENTA: TRANSFORMAÇÕES NO IDEÁRIO ${ }^{1}$
}

\author{
Michele Candiani Santos \\ Regina Helena Lima Caldana ${ }^{2}$ \\ Zélia Maria Mendes Biasoli Alves \\ FFCLRP-Universidade de São Paulo
}

\begin{abstract}
RESUMO: Este trabalho tem como objetivo estudar transformações ocorridas com o papel masculino no período compreendido entre os anos 40 e 90, através da análise das idéias veiculadas neste período pela revista Família Cristã. Foram selecionados para análise artigos que faziam referência aos papéis masculinos e/ ou femininos, nos exemplares de 1943, 1953, 1963, 1973, 1983 e 1993. Nos primeiros anos (1943 e 1953) a revista apresenta uma postura tradicional, porém já há destaque à afetividade masculina. O ano de 1963 configura-se como um marco, sendo o homem mais responsabilizado por suas ações na esfera doméstica. Valorizam-se, nos anos subseqüentes (1973-1993), a igualdade entre os sexos, um código moral simétrico e o modelo de pai amigo e marido participante. Este percurso evidencia a construção de um modelo masculino condizente com um modelo religioso de homem, já em curso nos anos anteriores à década de sessenta, mas intensificado desde então.
\end{abstract}

Palavras chave: Família, papel masculino, paternidade, gênero

\section{THE MALE ROLE FROM THE 1940'S TO 1990'S: MODELS TRANSFORMATIONS}

ABSTRACT: This paper aims to study the transformations of male roles from the 1940's to the 1990's, through analysis of the ideas circulated by "Família Cristã" magazine. Articles focusing on the male role in the issues of 1943, 1953, 1963, 1973, 1983 e 1993 were selected for analysis. In the early years (1943 and 1953) there was a traditional position in the magazine, but there was already a focus on male affectivity. The year of 1963 appears to be a landmark because the men are considered to be more responsible for their actions in the private sphere. In the following years (from 1973-1993) an equality between sexes, a symmetric moral code, and a model of a friend father and a participant husband are valorized. This is witnessed by the building of a male model consistent with a religious male model, already existent in the years before the decade of 1960 , but intensified since then.

Key words: Family, male role, fatherhood, gender.

A sociedade brasileira passou, ao longo da segunda metade do século XX, por um processo de modernização sócio-econômico-cultural que incluiu, entre outros, uma série de alterações nas características da estrutura familiar, com o desempenho cada vez mais intenso de tarefas não pertencentes tradicionalmente a cada gênero - o público para a mulher e

${ }^{1}$ Artigo recebido para publicação em 10 de 2001; aceito em março de 2002.

2 Endereço para correspondência: Regina Helena Lima Caldana, Depto de Psicologia e Educação, Faculdade de Filosofia, Ciências e Letras de Ribeirão Preto, USP, Av. Bandeirantes, 3900, Monte Alegre, Ribeirão Preto, SP, Cep 14040-901, e-mail: rhlcalda@ffclrp.usp.br o privado para o homem. Sob a marca principalmente do movimento feminista e da expansão do mercado de trabalho, que passa a incorporar de forma crescente o trabalho feminino, a profissionalização torna-se uma dimensão cada vez mais valorizada na vida da mulher, ocorrendo o inverso com seu papel no ambiente doméstico - o de "dona-de-casa". No mesmo movimento, as tarefas pertinentes a este último domínio passam a ser mais divididas com o homem, chamado inclusive a ter um papel ativo no cuidado $e$ educação dos filhos.

Poderíamos considerar expressivo desse mo- 
vimento o fato de ter havido, a partir dos anos setenta, um franco crescimento da literatura cujo objeto de estudo são os papéis e a identidade feminina. Mas o mesmo não ocorreu no que diz respeito a estudos que se voltam para as transformações ocorridas no papel masculino, e esta lacuna só mais recentemente começa a ser preenchida; é nesta direção que se estrutura este trabalho. E é importante destacar que em termos das relações de gênero, um papel só se define em relação ao outro, não se podendo compreendêlos isoladamente.

\section{O papel masculino: aspectos históricos}

As transformações contemporâneas pelas quais vêm passando o papel masculino não constituem as primeiras na história, nem tão pouco gozam de originalidade em seu conteúdo. Segundo Badinter (1993) existiram, na Europa e América do Norte, do século XVII ao final do século XIX, crises relativas ao papel masculino que, apesar de seus limites, alteraram a organização da família e do trabalho, abrindo caminho para as mudanças que assistimos hoje. Entre elas, a que se configuraria como mais extensa e profunda, que se inicia ao final do século $X X$, decorrente da industrialização, da democracia, e da maior escolarização da mulher, que deram novo alento às reivindicações feministas.

Focalizando esta temática no contexto nacional, não há como evitar a referência ao modelo de família patriarcal definido por Freyre (1933/1988) para o Brasil Colonial (Correa, 1982; Sâmara, 1983). Embora não se possa falar sobre "a família brasileira" como uma instituição com características únicas e gerais, independentemente de regiões ou de camadas sociais, o modelo descrito por Freyre (1933/ 1988), pela sua hegemonia como paradigma social, tem o peso de um ideal normalizador de caráter mais geral (Da Matta, 1987). Segundo ele, a vida familiar no Brasil colonial seria o resultado da herança cultural portuguesa aliada a uma economia latifundiária e escravista. Nela, consoante ao patriarcalismo, encontrar-se-ia uma marcante assimetria nas relações entre homens e mulheres, traduzida tanto em termos jurídicos quanto na vida cotidiana (Figueiredo, 1993; Samara, 1983; Teles, 1993). O senhor colonial detinha amplos poderes na esfera doméstica e fora dela, o que lhe permitia restringir o universo feminino a casa, mantendo a mulher sob total controle; cabia assim ao homem (e somente a ele), a circulação nos espaços públicos, de tal forma que o lar era reservado somente para aquelas atividades ligadas à alimentação e ao repouso (Costa, 1983).

Ao longo do século XIX, fruto da urbanização desencadeada pela vinda de D. João VI e da Corte para o Brasil, da penetração do capitalismo industrial europeu e a preocupação com o fortalecimento do Estado, aliada à ação da higiene (movimento higienista), houve uma remodelação significativa do espaço familiar. Este novo modelo consolidou-se no seio da família nuclear burguesa, e depois se expandiu para as camadas populares, num processo em que a Igreja Católica teve papel ativo ao se aliar e reforçar a ação da higiene (Winckler, 1983).

Segundo Costa (1983), nas novas condições que se criaram, o poder do homem diminuiu, pois o mundo urbano deixou de ficar sob a hegemonia de seu controle, e uma espécie de compensação ocorreu na relação com a mulher, com o machismo lhe permitindo a manutenção de certo domínio, ao menos sobre ela.

Apesar de conservar características do período anterior, as mudanças foram favoráveis ao papel feminino, pois com a valorização da função de mãe, a mulher é elevada à "categoria de mediadora entre os filhos e o Estado" (Costa, 1983, p. 73). A urbanidade $e$ a ação da higiene insuflaram este movimento, dando a ela uma nova posição enquanto consumidora de artigos industrializados, permitindo que se instruísse, lesse mais (novelas e romances) e entrasse em contato com as idéias de emancipação feminina que já circulavam nos EUA e na Europa. Por outro lado, numa vida social incrementada pela urbanização, a mulher passa a ter a tarefa de ser uma exímia anfitriã, como condição para o um bom encaminhamento do marido e filhos na carreira política e econômica. Em troca, ela começa a reivindicar um cuidado e uma atenção que nunca havia tido antes, preparando-se assim para receber as idéias de liberação feminina.

Na década de vinte, pelo menos nos grandes centros como São Paulo, com o ritmo acelerado das atividades e da industrialização, tornaram-se necessários novos meios de comunicação e transportes. 
Segundo Leite (1993, p.192), a família e a vida doméstica das mulheres viram-se invadidas "pela comunicação em massa e pressionada pelo novo ritmo de atrações veiculadas pelo cinema americano, que traziam os comportamentos diferentes da tal vida moderna".

E, em meio ao conservadorismo do país, surgiram algumas formas de feminismo, procurando defender os direitos da mulher à cidadania, à remuneração condigna e à maternidade consciente. Data desta época o desenvolvimento das organizações associativas de mulheres, cujos objetivos filantrópicos estenderam-se à política e à educação, entre as quais o grupo das sufragistas. $\mathrm{E}$, do ponto de vista profissional, nas camadas médias, eram aceitos como respeitáveis o magistério, o funcionalismo público e o jornalismo (Leite, 1993).

É somente nos anos 50, mas principalmente no período pós-64, que este padrão familiar burguês perderá sua estabilidade, e que novos modelos começarão a emergir, num processo em que a presença da indústria cultural, os movimentos da contracultura e feminista, e a difusão da Psicanálise foram importantes (Romanelli, 1987; Winckler, 1983). Nas décadas de sessenta e setenta todas estas idéias de emancipação explodem sendo inequivocamente percebidas e debatidas pelos diversos setores da sociedade brasileira.

Dois trabalhos (Alves,1985; Winckler, 1983) que tomam como material para suas análises produtos da indústria cultural - revistas masculinas e femininas - mostram as alterações dos papéis sexuais neste período. De acordo com suas análises, a modificação no padrão do comportamento é ambígua, pois, o conteúdo analisado tanto subsume uma maior liberdade sexual quanto reafirma valores afins a uma tradicional divisão de papéis ${ }^{3}$. Estes dois trabalhos, no entanto, focalizam o papel masculino na dimensão mais estrita da moral sexual.

Outros trabalhos voltados para o momento atual (Trindade, Andrade \& Souza, 1993; Rasera, 1994; Romanelli,1987; Silva \& Lago, 1994) procuram focalizar as alterações em outros domínios do privado. Segundo esses trabalhos, que têm como dados principais os obtidos através de entrevistas,

\footnotetext{
${ }^{3}$ O título do trabalho de Alves (1985) é eloquente: $A$ velha-mulhernova e o machão-moderno.
}

no que diz respeito à construção de um modelo mais igualitário de relacionamento entre o homem e a mulher, está-se efetivamente diante de um processo de alterações de papéis muito lento, em que permanências e inovações convivem num conjunto em que predomina a ambigüidade.

\section{Método}

Este trabalho tem como objetivo estudar transformações ocorridas no papel masculino, em sua interação com o feminino, no período compreendido entre os anos 40 e 90, no Brasil, através da descrição das suas características, tal como veiculada pela revista Família Cristã, uma publicação mensal da ordem dos Paulinos, regular desde 1935, destinada ao público laico e voltada para temas ligados à vida familiar.

A opção pela análise do conteúdo presente em uma revista parte do pressuposto de que este tipo de veículo, sendo produto da indústria cultural, ao mesmo tempo reflete e constrói o processo de redefinição social de modelos de conduta e valores (Romanelli, 1987; Alves, 1985).

A revista "Família Cristã", especificamente, é uma publicação que preserva homogeneidade em sua estrutura ao longo do tempo, e, portanto permite clareza na percepção das permanências e alterações (Caldana, 1991 \& Prandi, 1975). É ainda uma publicação ligada à Igreja Católica, uma instituição fundante na sociedade brasileira, que têm mostrado uma grande capacidade de se adaptar e manter atuante ao longo do tempo, com envolvimento direto e ativo no que diz respeito a papéis e valores familiares (Ribeiro, 1987).

Foram analisados qualitativamente 72 exemplares da revista ${ }^{4}$, referentes aos 12 números respectivamente dos anos de 1943, 1953, 1963, 1973, 1983 e 1993. A análise do material seguiu os seguintes passos:

1. Uma leitura integral inicial de cada exemplar da revista para uma caracterização geral do veículo no período (década);

2. Uma segunda leitura para seleção dos artigos que faziam referência, direta ou indireta, aos papéis

${ }^{4}$ Familia Cristã, São Paulo, Ed. Paulinas, volumes 9 (1943), 19 (1953), 29 (1963), 39 (1963), 49 (1973) e 59 (1993). 
masculinos e femininos;

3. A classificação dos artigos selecionados conforme o papel de gênero a que se referiam: Feminino, Masculino ou Ambos, considerando-se como artigo referente exclusivamente ao papel masculino ou feminino aquele que tratava exclusivamente de um ou outro (homem ou mulher) e caindo na categoria ambos quando versavam sobre os dois papéis simultaneamente.

4. A classificação segundo o interlocutor expresso (Homem, Mulher ou Geral), ou seja, a quem eles se dirigem textualmente, sendo que aqueles que apresentavam algum tipo de chamamento ao homem ou à mulher, mostrando assim serem dirigidos principalmente a um dos dois, foram classificados como Homem ou Mulher. Os que não traziam especificação foram considerados como destinados ao público em Geral.

5. Afora uma primeira análise, que é do formato da revista e que, portanto traz uma descrição com base em números, seu conteúdo é visto sob um enfoque qualitativo e estabelece-se uma comparação dos artigos, feita de acordo com o modelo proposto por Biasoli-Alves \& Dias da Silva (1992); segundo esses autores, o trabalho de análise pode ser descrito como uma sistematização, produto de um movimento constante entre os dados, a abordagem conceitual e a literatura, com $o$ intuito de alcançar um quadro significativo e compreensivo da realidade.

\section{Resultados}

\section{A caracterização geral da revista}

No ano inicial analisado, cada número da revista compõe-se de 16 páginas e uma média de 22 artigos (tabela 1) com extensão variável e não assinados. Oito seções são definidas, sendo assuntos mais freqüentes a doutrina religiosa católica, questões familiares (em especial os deveres da esposa/mãe e a educação dos filhos) e a formação moral (sobretudo a da jovem). O estilo utilizado é predominantemente narrativo, em pequenos episódios (históricos ou fictícios) com o intuito de ensinar e orientar o leitor no campo moral; a linguagem faz apelo à emoção, recorrendo a muitos adjetivos, advérbios e pontos de exclamação, para apresentar idéias extremadas (bem/ mal, virtude/pecado, Deus/diabo) que se repetem.

Em 1993, marco final da análise, encontra-se cada exemplar da revista com 74 páginas, uma média de 30 artigos, 21 seções fixas (tabela 1), com sequiência definida de apresentação e a presença de sumário e editorial. Temas sociais e religiosos são abordados com maior frequiência, ao lado dos relacionados a comportamento, voltados para família, casal e educação de filhos, com ênfase nos aspectos morais e psicológicos, destacando-se este último, a partir da opinião de psicólogos, psiquiatras e psicanalistas. O estilo e a linguagem têm tom jornalístico voltado à transmissão de informações.

Do ano de 1943 ao de 1993, o processo de transformação é gradual, sendo que a década de setenta parece ser um ponto de inflexão: o número de páginas aumenta para quase o dobro (tabela 1), e as temáticas, com pouco espaço para o conteúdo religioso, aproximaram-na de uma revista de variedades; além disso, é então que o estilo e linguagem utilizados adquirem predominantemente o tom jornalístico contemporâneo.

Tabela 1: Número médio de páginas, artigos e seções fixas dos números da Revista Família Cristã nos anos analisados.

\begin{tabular}{c|c|c|c}
\hline ano & $\begin{array}{c}\text { número de } \\
\text { páginas }\end{array}$ & $\begin{array}{c}\text { número de } \\
\text { artigos }\end{array}$ & $\begin{array}{c}\text { número de } \\
\text { sessóes fixas }\end{array}$ \\
\hline $\mathbf{1 9 4 3}$ & 16 & 22 & 8 \\
1953 & 20 & 19 & 11 \\
$\mathbf{1 9 6 3}$ & 35 & 22 & 19 \\
1973 & 68 & 24 & 22 \\
$\mathbf{1 9 8 3}$ & 74 & 24 & 20 \\
$\mathbf{1 9 9 3}$ & 74 & 30 & 21 \\
\hline
\end{tabular}

\section{Os artigos selecionados: o papel de gênero focali-} zado e o interlocutor

Quando se observam as tabelas 2 e 3, vê-se que nos artigos selecionados para análise, tanto em relação ao papel de gênero focalizado quanto ao interlocutor expresso, a década de sessenta e setenta configuram-se como um período de mudanças cujo sentido se acentua nos anos oitenta e noventa: deixa-se de focalizar maciçamente o papel feminino, 
para abrir espaço para o masculino ou para a consideração de ambos em conjunto; da mesma forma a revista deixa de falar exclusivamente às mulheres para dirigir-se não ao homem, mas a um leitor universal, sem diferenciação de gênero.

Tabela 2: Frequiência simples e porcentagem de artigos selecionados para análise, segundo papel de gênero focalizado e ano da Revista.

\begin{tabular}{c|c|c|c|c|c|c|c|c}
\hline ano & \multicolumn{2}{|c|}{ masculino } & \multicolumn{2}{c|}{ feminino } & \multicolumn{2}{c|}{ ambos } & \multicolumn{2}{c}{ Total } \\
& \multicolumn{2}{|c|}{} & \multicolumn{2}{|c|}{} & \multicolumn{2}{c}{} & \multicolumn{2}{c}{} \\
\hline 1943 & 08 & $14 \%$ & 31 & $55 \%$ & 19 & $31 \%$ & 58 & $100 \%$ \\
1953 & 05 & $17 \%$ & 19 & $63 \%$ & 06 & $20 \%$ & 30 & $100 \%$ \\
1963 & 11 & $24 \%$ & 10 & $22 \%$ & 25 & $54 \%$ & 46 & $100 \%$ \\
1973 & 11 & $22 \%$ & 10 & $20 \%$ & 29 & $58 \%$ & 50 & $100 \%$ \\
1983 & 17 & $31 \%$ & 11 & $21 \%$ & 26 & $48 \%$ & 54 & $100 \%$ \\
1993 & 25 & $35 \%$ & 09 & $12 \%$ & 38 & $53 \%$ & 72 & $100 \%$ \\
\hline
\end{tabular}

Tabela 3: Freqüência simples e porcentagem de artigos selecionados para análise, segundo interlocutor expresso e ano da Revista.

\begin{tabular}{c|c|c|c|c|c|c|c|c}
\hline Ano & \multicolumn{2}{|c|}{ homem } & \multicolumn{2}{c|}{ mulher } & \multicolumn{2}{c|}{ geral } & \multicolumn{2}{c}{ Total } \\
\hline 1943 & 08 & $14 \%$ & 48 & $83 \%$ & 02 & $03 \%$ & 58 & $100 \%$ \\
1953 & 03 & $10 \%$ & 25 & $83 \%$ & 02 & $07 \%$ & 30 & $100 \%$ \\
1963 & 04 & $09 \%$ & 05 & $11 \%$ & 37 & $80 \%$ & 46 & $100 \%$ \\
1973 & 01 & $02 \%$ & 02 & $04 \%$ & 47 & $94 \%$ & 50 & $100 \%$ \\
1983 & - & - & - & - & 54 & $100 \%$ & 54 & $100 \%$ \\
1993 & - & - & - & - & 72 & $100 \%$ & 72 & $100 \%$ \\
\hline
\end{tabular}

\section{O homem}

Os modelos

Nos os anos 43 e 53 é na imagem de $S$. José que o homem deve se mirar para que "aprenda a ser pai, amor e providência de seus filhos" (Destéfani, 1953, p.15) caracterizando-o como um modelo para todas as esferas, mas com destaque à paternidade. Esta figura gradualmente perde sua ênfase e, em 73, é o homem público, por sua atuação ligada à política, quem surge como modelo. Neste caso, junto às qualidades no campo profissional e intelectual, aparecem as do lado humano e familiar, de tal forma que estão conciliados trabalho e família, racionalidade e afetividade.

Em 83 a figura ideal é Jesus Cristo, sendo ressaltada sua coragem para defender o próximo, exemplo importante para o empenho em obras sociais. Mas, também já está presente nesta data e mais acentuadamente em 93 , a preocupação maior da $\mathrm{FC}^{5} \mathrm{com}$ um modelo universal de pessoa cristã, acima de qual-

\footnotetext{
${ }^{5}$ Revista Família Cristã
}

quer diferenciação de gênero. Nas escassas referências diretas ao papel masculino as características gerais veiculadas pela revista são: a ênfase na religiosidade, compreensão e outras virtudes a serem desenvolvidas. Neste sentido, algumas das figuras exemplares são padres e psicólogos ou psicanalistas.

A religiosidade masculina

Nas décadas de quarenta e cinqüenta, o homem aparece como quem deve ser conduzido à fé pela sua principal agente catequizadora: a mulher. Em 63, a religiosidade masculina passa a ser tratada diretamente pela revista, e a necessidade de uma formação religiosa sólida é apontada, principalmente perante a intenção de constituir uma família. No ano de 73 esta questão fica em segundo plano, mas, a partir de 83 , a revista toma uma posição que se solidificará em 93, segundo a qual o ideal é um cristão responsável por sua própria fé e relação com Deus, e também um catequizador no sentido social, pois deve ajudar os outros - entre os quais seus filhos - a se 
encontrarem com a religião.

Trabalho

Nos três primeiros anos analisados, o campo do trabalho é praticamente colocado como área diferenciadora do masculino. É nela que o homem afasta-se da mulher, e nela alcançará sua dignidade, base para uma família feliz.

Nos últimos anos, surge uma tendência que se estabilizará em 93 e que coloca o trabalho como necessário, mas devendo ser exercido de forma a não se sobrepor à vida familiar e às qualidades pertinentes ao âmbito da vida privada.

\section{Virilidade}

De 43 a 63, a virilidade da figura masculina é destacada em $S$. José, por sua força de caráter e aparência física máscula "um nariz grande e nobre, braços musculosos" (São José, 1943). Em 63, paralelamente, a revista sinaliza a necessidade do cuidado com a aparência, incluindo-se o apuro no vestir: é então que se encontrarão as primeiras fotos masculinas na sessão de Moda, e artigos versando sobre a relação do homem com a aparência física. Em 73, o destaque vai para o homem delicado, cavalheiro, que deve buscar um equilíbrio entre força e afetividade. Mas curiosamente, em 93, ainda estão presentes os exemplos de histórias bíblicas com personagens masculinos marcados pela força de caráter e/ou virilidade, num sentido mais próximo aos dos anos iniciais.

\section{Homem e mulher}

\section{Casamento}

Valor intocável em todos os anos analisados, o "matrimônio é santo (...) e simboliza a união íntima de Cristo com a Igreja" (A Família Cristã, 1943, p.8). Para seu sucesso, de 43 a 63, o essencial é que o homem encontre uma boa esposa, que tenha dotes domésticos e morais, considerados mais importantes que beleza, iniciativa e inteligência.

É pouco enfatizado o inverso, o homem colocado como objeto de cuidado na escolha da mulher, para que ela não sofra com um mau casamento. Ele efetivamente não é visto como responsável pelo relacionamento do casal, muito menos pelo que acontece no ambiente doméstico, onde deve ser muito bem cuidado e respeitado pela esposa e filhos. As obrigações são, portanto distintas, e o funcionamento das relações segue um acordo tradicional. No que diz respeito à religião, no entanto, a revista afirma que os deveres são iguais para ambos os cônjuges.

Em 63, o homem passa a ser responsabilizado indiretamente pelo sucesso do casamento, sendo colocado como dependente da mulher para conduzir sua vida familiar e encarado como razoavelmente incompetente para os assuntos do lar. Mas a diferença entre os sexos é ainda o que recebe destaque, sendo a complementaridade de papéis o que determinaria o par perfeito, e que, de alguma forma, possibilitaria o alcançar de "certa igualdade", que aparece como uma tênue preocupação.

Neste periodo, o amor recebe destaque e o homem é considerado menos apto para amar do que a mulher, devendo, por isso, ser ensinado e desenvolver $a$ afetividade através da postura feminina. Ele, através do amor, deve ser fonte de proteção e compreensão para sua mulher. A delicadeza masculina, característica que faz parte do ideal masculino de cavalheirismo, surge como imprescindível no relacionamento do casal.

Em 73, detecta-se uma transformação nessas atribuições, principalmente nas femininas, e a ênfase passa ao companheirismo: o parceiro procurado, pelo homem ou pela mulher, é aquele capaz de compartilhar a vida e dividir as responsabilidades.

Se em 83 o importante é o indivíduo, independente do gênero a que pertence, a tendência é a de se falar mais do casamento do que dos papéis específicos de marido e esposa, que se diluem na divisão das tarefas familiares e conjugais. $\mathrm{O}$ amor entre os cônjuges continua sendo considerado central e o homem é cada vez mais visto como responsável pelo transcorrer da vida conjugal e doméstica. Às vezes, no entanto, as responsabilidades femininas são enfatizadas como nos anos anteriores, e considerase que os papéis sexuais se identificam e se contrapõem, em exercício contínuo que formará a personalidade feminina e masculina. Mas a diferenciação no papel social de gênero em si mesma é muitas vezes vista negativamente, como algo que "sufoca" a pessoa e a liga ao modelo tradicional; no caso específico do homem, pode aprisioná-lo de tal forma que criará dificuldades em seu relacionamento com a fa- 
mília. Dentro desta combinação não uniforme de tendências, veicula-se um ideal de igualdade nas formas de cortejo, mas admite-se a existência de diferenças culturais.

Em 93, apesar do empenho em superar a diversidade, a publicação, às vezes, mostra que os estereótipos tradicionais, em que a mulher é vista como pertencendo à esfera privada (lar, família) e o homem à pública (mundo do trabalho), persistem. $\mathrm{O}$ que a revista propõe é que o homem passe a cultivar a esfera privada do lar, pois somente na vida familiar alcançaria a verdadeira felicidade e realização.

Neste período, também em relação à sexualidade, há o esforço em apagar as diferenças de gênero, numa visão que abole a dicotomia alma/corpo, considerando-se a sexualidade integrada como expressão de comunhão, e sendo o mais importante em um relacionamento heterossexual não o sexo, mas o amor-amizade. E numa regra que vale para homens e mulheres, o lugar correto do sexo seria no e depois do casamento.

\section{Poder, hierarquia e moral}

Consoante à análise acima, de 43 a 63 o homem é retratado em posição de superioridade perante a mulher. Entretanto, neste mesmo período, ela, principalmente a que é mãe, é vista como portando um poder incalculável e sobrenatural, numa "superioridade" que só aparece de forma indireta, através de elogios à sua atuação.

Neste jogo, se todas as responsabilidades no casamento são suas, resta ao marido "receber dela os ensinamentos do caminho da virtude", sendo a fortaleza moral uma das (ou talvez a maior) fontes de seu poder, considerada como superior à masculina; isto está em conformidade com um código moral assimétrico em que à mulher cabe a posição de tutora do desejo masculino, tendo liberdade para escolher o que se tornará, se "instrumento do demônio" e então responsabilizada pelo descontrole do marido, justificando que ele use de violência para com ela, e que ela seja culpabilizada pelos fracassos do casamento, mesmo sendo ele quem "peca" - ou a "esposa santificada".

Pouco a pouco, o homem começa a ser chamado a desenvolver virtudes morais muito próximas às femininas. Com a presença de ambivalência gera- da pela coexistência de artigos que defendem posições contraditórias, a revista chegará em 93 condenando abertamente o código moral anterior e propondo um simétrico.

\section{O homem e os filhos}

Em 43, ao lado do predomínio do modelo tradicional, em que o pai é o chefe (distante) da família, que participa da educação dos filhos somente através da mediação da esposa, a revista veicula uma figura paterna mais afetiva e próxima dos filhos que gradativamente se fortalece e, em 63 , a distância entre este modelo e a realidade dos leitores aparece na constatação de que o pai de então é um omisso.

Instado a assumir seus deveres, o pai é lembrado de que sua autoridade é dada por Deus, não apenas para ordenar, castigar ou estar por perto fisicamente, mas para cuidar da formação total dos filhos, numa relação profunda em que se deve "adentrar a alma do filho". Este modelo de maior proximidade irá se estabelecer em 73 na figura do pai amigo, que mantém aberto o canal de comunicação. A questão do diálogo passa a ser central na revista, pois é preciso saber o que pensa e quer o filho, devendo o pai estar sempre à disposição para uma conversa.

Mas há contradições, e ora aparece este pai amigo e "enérgico" (que dá limites), ora o amigo que nada impõe, dando ampla liberdade, sendo mal vistos aqueles que mantêm uma postura distante, rígida e autoritária, cuja punição é o afastamento dos filhos. E é ainda o homem quem continua, segundo a revista, a fazer a ponte entre o mundo privado familiar e o exterior.

Em 93, uma nova viravolta, com a crítica ao "pai amigo", que estaria levando a uma permissividade não recomendável, propondo-se uma educação equilibrada, um meio termo entre a "tradicional", em que as proibições são inúmeras, e a "moderna", em que tudo é permitido. Obviamente, a afetividade e a amizade entre pais e filhos não são excluídas, devendo-se ponderar a autoridade.

\section{A educação do menino}

Em 43 há um modelo de educação de meninos em que características mais afetivas e ternas re- 
cebem ênfase, estando afinado à religiosidade e não se mostrando diferente para as meninas, com destaque para a pureza moral e a espiritual. Mas, em um aspecto existe discrepância porque somente as meninas são tratadas desde cedo como mãezinhas em miniatura, "o anjo da casa" que ajuda toda a família, num modelo que valoriza seu amadurecimento precoce.

Em 53, parece existir um reforço ao modelo tradicional: o menino é colocado como um homenzinho, cujas principais qualidades são sua força de caráter, independência e senso de proteção à família, características estas que não são compartilhadas por sua irmã, que continua a ser considerada a futura mãe e mulher que depende de um homem.

Em 73, há uma mudança que persiste em 83 , pois a revista fala claramente que a atual educação dada às meninas deve ser diferente da antiga, e a dos meninos também, pois eles, mesmo não sendo treinados como mãezinhas, precisariam aprender tarefas domésticas tradicionalmente femininas.

Os dados de 93 são interessantes, pois ao lado da manutenção de um discurso que fala sobre a educação de filhos, sem especificidade de gênero, há a veiculação de uma peça teatral a ser montada por ocasião do dia dos pais, em que os modelos são estereótipos tradicionais: os papéis dos meninos são ativos, de coragem e curiosidade, e os das meninas passivos, emotivos e secundários; e, numa seção destinada às crianças - "As crianças e a Bíblia", os personagens centrais são todos masculinos (Sansão, Samuel, Davi, Salomão, Elias, Isaías, Jeremias, Ezequiel, Jesus), numa ênfase sutil a uma visão tradicional, reservando, ao futuro homem, um lugar de destaque ainda nesta década.

\section{Discussão}

É importante que o panorama acima traçado, com certeza rico e complexo, possa ser comentado de acordo com um eixo tríplice, que compreenda, além das transformações de mentalidade propriamente ditas, o posicionamento da Igreja Católica e o contexto sócio-histórico-cultural do Brasil. Nosso intuito não é uma interpretação exaustiva e acabada desses dados, que fogem à possibilidade de qualquer generalização simplista, mas sim apontar aspectos que parecem importantes na compreensão das continuidades e rupturas daquilo que caracteriza o papel masculino, e de seu possível significado.

Retomando o percurso visto, volta-se a São José como modelo e ideal de homem em 1943, figura que congrega em si vários aspectos tradicionais: é o chefe da família, a quem se deve obediência; permanece distante da educação de seu filho, tem sua esposa, Maria, como intermediadora nesta relação e na que mantém com Deus; e seu principal espaço de ação é o trabalho (esfera pública), que o diferencia da mulher, confinada, ao lar.

Para contextualizar esses dados de 43, em primeiro lugar, vale a pena considerar que a revista $\mathrm{Fa}$ mília Cristã foi criada na década de trinta, em que, tanto a Igreja Católica brasileira quanto o país viviam um momento muito particular, pós Revolução, caracterizado pelo processo de urbanização e fortalecimento da classe média (Azzi, 1993), estando a Igreja Católica brasileira começando a enfrentar a concorrência de outras religiões como o protestantismo, pentecostalismo e espiritismo (Bruneau, 1979). De um lado há aproximação com o Vaticano, num processo conhecido como romanização da Igreja, e de outro mantém forte aliança com o Estado, que lhe fazia concessões vantajosas, tais como o reconhecimento do casamento religioso pela lei civil e a proibição do divórcio (Camargo, 1971; Morais, 1982; Pucci, 1985; Romano, 1979).

É compreensível então o tom dos artigos de 43 , que defende os ideais tradicionais, apresenta o catolicismo como única verdade sobre o homem, $\mathrm{e}$ demonstra verdadeiro pavor às doutrinas sociais como o comunismo, anarquismo e socialismo, auxiliando o Estado a combatê-los. Apesar desta postura tradicional, FC traz um elemento destoante: o homem deve desenvolver características afetivas, afinadas à religiosidade, e que ponderarão sua autoridade. São José é colocado como um homem sereno, manso, que ama sua família e gosta de crianças, e nesse sentido encontramos em sua figura as raízes do modelo de pai e amigo presente em 1973.

Os dados de 53 diferem pouco dos de 43 , porém já começam a aparecer questionamentos aos papéis tradicionais, principalmente ao código moral assimétrico, abrindo espaço em suas páginas para algumas idéias sobre a emancipação da mulher. A 


\section{O Papel Masculino 65}

revista continua defendendo uma nítida divisão de funções, porém as admoestações que dirige ao homem que é pai incluem o envolvimento afetivo na educação dos filhos.

É em 1963, que o número de artigos referentes exclusivamente ao papel masculino praticamente se iguala aos femininos, numa mudança radical. Também é nesta década que se incrementa o debate na revista sobre os papéis, demonstrando uma abertura ao modelo igualitário: o homem continua a ser o chefe, mas agora é responsabilizado por sua conduta moral, religiosa e matrimonial. É questionada a sua omissão nas áreas domésticas. Assim, ao mesmo tempo em que reforça o poder masculino afirmando que a figura paterna é divina, ela defende claramente a idéia de participação masculina ativa e afetiva na educação da prole.

Essa abertura e contradições relacionam-se, provavelmente, com o debate interno da Igreja durante o Concílio Vaticano II (1962-1965), que levou a uma "mudança de rumos", afinando-se seu discurso às grandes transformações havidas no mundo ocidental. Em uma sociedade cada vez mais secularizada, fazia-se inevitável a aliança da Igreja com a ideologia científica e tecnocrática. Por outro lado, a atuação da Conferência Nacional dos Bispos do Brasil, voltada para conter a perda de fiéis para os "concorrentes" (protestantismo, a umbanda e o marxismo), cria uma modalidade de atuação que tenta conciliar a atividade interna da Igreja e suas funções sociais, sustentando oficialmente o desejo da participação católica ativa nas transformações das instituições e na vida brasileira (Pucci, 1985).

Este quadro torna-se muito mais significativo perante o incremento da industrialização que teve seu maior impulso no governo de Juscelino (195661), com o qual consolidou-se e expandiu-se o capitalismo associado ou dependente. Como decorrência, chegam ao país as grandes multinacionais, a influência norte americana cresce, e abre-se espaço à exacerbação do consumo, à ênfase ao científico e tecnológico e à valorização do "novo" em detrimento das tradições.

Nesse cenário torna-se compreensível que a figura de São José perca espaço nas páginas da revista enquanto modelo e que a preocupação com a aparência estética e a moda tornem-se válidas tam- bém para o homem, em conformidade com uma tendência de maior consumo e um padrão "hollywoodiano". O ideal de igualdade entre os sexos, referido e defendido pela revista no período, pode ser incluído na ideologia da "modernização" que operava no Brasil desde o final da década de cinqüenta, paralelamente a uma industrialização mais avançada (Durham,1983). Mas o modelo igualitário produz, como bem atestam as contradições da revista, uma situação instável, sendo formal dentro de uma cultura de classe, mas agenciado pela família de modo pessoal, como regulador da relação de "pessoas diferentes" (homens e mulheres).

No intervalo entre os anos sessenta e setenta, o país assiste ao golpe militar, que significou a retomada do modelo econômico formado pela aliança entre setores mais dinâmicos do capitalismo industrial, nacional e internacional, e que levou ao "milagre brasileiro" (Pucci, 1985). Neste contexto, a Igreja divide-se ideológica e politicamente, definindose o grupo dos progressistas, que ganhará paulatinamente espaço sob o influxo da Segunda Conferência do Episcopado da América Latina (CELAM), ocorrida em 1968 (Della Cava, 1986). Por outro lado, em termos culturais, marca-se a influência dos movimentos juvenis contestatórios e de contracultura, dos de emancipação feminina e, ainda, a emergência da Psicologia como orientadora de condutas.

É neste quadro que a FC sofre uma mudança formal radical, aumentando seu número de páginas, diminuindo a presença de artigos religiosos, transformando-se numa revista de variedades, consoante ao ritmo de desenvolvimento e progresso que se respirava no país. É o contexto político que torna compreensível a adoção do homem público, político, como ideal masculino; e a atenção especial dada aos jovens é pertinente perante uma preocupação despertada pelos movimentos contestatórios e de contracultura.

Da mesma forma pode-se compreender os modelos de comportamento para a família, com a solidificação da idéia do pai amigo, a ênfase na importância do diálogo como um instrumento para a manutenção dos relacionamentos entre pais e filhos, e cônjuges, com a voz cada vez mais forte dos especialistas, principalmente médicos e psicólogos.

É interessante observar o jogo que se estabe- 


\section{Michele Candiani Santos}

lece: dentro de certa "modernização", a revista se esquiva de falar sobre algumas questões tais como a liberdade sexual e o divórcio. Defende o trabalho feminino, mas com cautela, quando ele é necessário para a família; mostra-se aberta à educação de filhos homens que inclua mais e mais a afetividade e participação no ambiente doméstico, mas propõe um código moral simétrico para homens e mulheres, que significa não liberdade sexual, parabenizando o homem que cultive, como a mulher sempre precisou fazê-lo, a castidade. E, porque o lazer e a diversão são destacados e recomendados, fica claro que a revista acompanha o processo de industrialização e o desenvolvimento da sociedade de consumo.

Os anos 80 são palco de um alinhamento francamente progressista, na opção preferencial pelos pobres, na promoção e defesa da dignidade da pessoa humana e na dimensão política e social da fé (Pucci, 1985). O ideal masculino agora é o homem cristão que vive para sua família (se casado) e para seu próximo; que deve desenvolver virtudes, como a coragem, para que possa defender os desfavorecidos, fazendo disso sua missão. Padres e missionários preencherão perfeitamente este modelo.

$O$ esforço da Igreja para se manter atuante, num mundo em mudança, e num país em desenvolvimento como o Brasil, faz com que ela se direcione para as classes desfavorecidas, reelaborando sua concepção da vida em sociedade, tentando, como diz Prandi (1975), não mais falar aos homens, e sim falar pelos homens. Esse novo caminho, significa uma recuperação da dimensão religiosa, trazendo maior coesão em sua composição (Caldana, 1991), mas, por outro lado, implica em continuar a se calar diante de alguns aspectos da modernidade que se contrapõem aos princípios religiosos. E na esteira da III $^{\mathrm{a}}$ Conferência do Episcopado Latinoamericano de Puebla, de 1979, a defesa dos direitos humanos alimenta a fogueira da ideologia igualitária, presente na sociedade e defendida pela revista. Homem e mulher percebem-se como diferentes, pessoal e idiossincraticamente (Figueira; 1983), mas como iguais porque indivíduos; na família igualitária, proposta pela revista, o que limita a pluralidade de escolhas do indivíduo no mundo é somente o respeito à individualidade do outro, algumas regras morais $\mathrm{e}$ religiosas em que ela insiste.
O papel masculino, então, mescla-se definitivamente ao feminino (Banditer, 1993) ${ }^{6}$. A delicade$\mathrm{za}$, a pureza, os altos ideais morais e sociais, o cultivo da intimidade e felicidade no lar são características masculinas, e não mais exclusivas das mulheres. Há uma valorização do privado, e um convite é feito ao homem: que direcione cada vez mais sua atenção ao lar e a família, pois é aí que está sua felicidade. A valorização do íntimo, do privado, do pessoal e familiar, produto típico do capitalismo individualista, numa tendência que já dava mostras de si, na revista, desde 43 , apresenta-se no seu auge.

Olhar para os anos noventa é mais difícil. É um período temporalmente muito próximo e objeto de pouca literatura analítica, principalmente focalizando a Igreja Católica. Nele, pode-se ver que o ideal de homem cristão, envolvido com projetos sociais persiste, mas de forma muito mais "diluída"; por outro lado, o discurso igualitário não só continua como se torna a principal forma da revista dirigir-se a seus leitores. Ao mesmo tempo, aparece a crítica ao pai amigo, acusado de omissão e perda de referenciais, numa admoestação dirigida também à mãe. Mas não há propostas diferentes e reforça-se este mesmo modelo. É interessante o aumento significativo no número de artigos que focalizam exclusivamente figuras masculinas. Embora não versem diretamente sobre gênero, possivelmente indicam um reforço indireto ao universo masculino mais convencional, colocando-o sutilmente no lugar de destaque e ação.

Parece-nos apontado aqui mais um sinal da presença de um movimento de fluxo e refluxo na preponderância das diferentes características do papel masculino; e o espaço concedido à Psicologia e Psicanálise é condizente com a colocação de Figueira (1983, p. 145) segundo a qual esses saberes teriam a função de "discriminador neste carnaval de identidades" e papéis instáveis. E, é bom lembrar, esta vertente psicologizante advém e alimenta as ideologias individualistas, tornando-se o sujeito psicológico a medida de todas as coisas (Velho, 1985; Figueira,1983). Para Velho (op. cit.) a psicologização tende a nos fazer ver a questão da descontinuidade (Nicolaci-da-Costa, 1987; Figueira, 1985) entre os

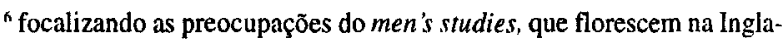
terra. EUA, Austrália e países nórdicos. 
diversos modelos sociais e seus conflitos como uma questão pessoal, individual e interna. E com efeito, pode-se dizer que revista está sempre instando para que seus leitores se "auto-regulem", oferecendo-lhes ideais para serem seguidos, e, perante a dificuldade em lidar com as idéias e transformações que circulam no contexto sócio-econômico-cultural, as delícias do lar e da família representariam um ideal a ser alcançado.

\section{Referências Bibliográficas}

A Família Cristã (1943). Família Cristã, 09, p. 08.

Alves, D. (1985). O desencontro marcado - a velhamulher-nova e o machão-moderno. Petrópolis: Vozes.

Azzi, R. (1993). Família, mulher e sexualidade na Igreja do Brasil (1930-1964). Em M.L Marcílio (Org.), Familia, mulher, sexualidade e Igreja na história do Brasil (p.101-134). São Paulo: Ed. Loyola e CEDHAL/CEHILA.

Badinter, E. (1993). Prólogo: O enigma masculino. Em E. Badinter, $X Y$ - Sobre a identidade masculina (M. I. Duque Estrada, Trad, p. 1-29). Rio de Janeiro: Ed. Nova Fronteira.

Biasoli-Alves, Z.M.M. \& Dias dA Silva, M.G.F. (1992) Análise qualitativa de dados de entrevista Cadernos de Psicologia e Educação Paideia 2, 61-9.

Bruneau, T.C. (1979). Religião e politização no Brasil: a Igreja e o Regime autoritário. São Paulo: Loyola.

Caldana, R.H.L. (1991). Família, mulher e filhos Três momentos numa revista católica brasileira (1935 a 1988). Dissertação de Mestrado, Universidade Federal de São Carlos, São Carlos.

Camargo, C.P.F. (1971). Igreja e desenvolvimento. São Paulo: Ed. Brasileira de Ciências Ltda/ CEBRAP.

Costa, J.F. (1983). Ordem médica e norma familiar. Rio de Janeiro: Graal.

Da Matta, R. (1987). A família como valor: considerações não familiares sobre a família brasileira. Em A. M. ALMEIDA (Org.), Pensando a fami- lia no Brasil: da colônia à modernidade (pp. 115136). Rio de Janeiro: Espaço e Tempo.

Della Cava, R. (1986). A Igreja e a Abertura, 19741985. Em: P. Krischke \& S. Mainwaring (Orgs.), A Igreja nas bases em tempo de transição (19741985).(pp.13-45), Porto Alegre: L \& PM/ CEDEC.

Destéfani, Frei B. (1953, março). São José e a família. Família Cristã, 19, p. 15.

Durham, E.R. (1983). Família e reprodução humana. Em E.R. Durham (Org), Perspectivas antropológicas da mulher 3. (pp.13-44) Rio de Janeiro: Zahar.

Figueira, S.A. (1983). O "moderno" e o "arcaico" na nova família brasileira: notas sobre a dimensão invisível da mudança social. Em S.A. Figueira (Org.), Uma nova família? $O$ moderno e o arcaico da familia de classe média brasileira (pp.11-30), Rio de Janeiro: Zahar.

Figueira, S.A.(1985). Modernização da família e desorientação: uma das raízes do psicologismo no Brasil. In: Figueira, S. (Org.) Cultura da Psicanálise ( $p p$. 142-146). São Paulo: Brasiliense.

Figueiredo, L. (1993). O avesso da memória: cotidiano e trabalho da mulher em Minas Gerais no século XVIII. Rio de Janeiro: José Olympio.

Freyre, G. (1933/1988). Casa grande e senzala. Rio de Janeiro: Jorge Zahar Editores.

Leite, M.A.M.(1993). A mulher das camadas médias entra no mercado de trabalho. Em M. L. Marcílio (Org.), Família, mulher, sexualidade e Igreja na história do Brasil (pp.191-196). São Paulo: Ed. Loyola; CEDHAL/CEHILA.

Morais, J.F.R. de (1982). Os bispos e a política no Brasil. São Paulo: Cortez.

Nicolaci-da-Costa, A.M. (1987). Sujeito e cotidiano: um estudo da dimensão psicológica do social. Rio de Janeiro: Campus.

Prandi, J.R. (1975). Catolicismo e família: transformações de uma ideologia. Cadernos CEBRAP, 21. São Paulo.

Pucci, B. (1985). A nova práxis Educacional da Igre- 
68 Michele Candiani Santos

ja (1968-1979). São Paulo: Ed. Paulinas.

Rasera, E.F. (1994). Identidade masculina e subjetividade: universitários de Ribeirão Preto. (Monografia de Bacharelado) Ribeirão Preto: Universidade de São Paulo/Faculdade de Filosofia, Ciências e Letras de Ribeirão Preto.

Ribeiro, I (1987). Prefácio Em I. Ribeiro (Org.), Sociedade brasileira contemporânea: família $e$ valores (p. 9-11). São Paulo: Loyola.

Romanelli, G. (1987). Famílias e camadas médias: a trajetória da modernidade. Tese de Doutorado, Universidade de São Paulo/Faculdade de Filosofia, Letras e Ciências Humanas.

Romano, R. (1979). Brasil: Igreja contra Estado. São Paulo: Kairós.

Samara, E.M. (1983). A família brasileira. São Paulo: Brasiliense.

São José, (1943, março). Família Cristã, 09, p. 16.

Silva, J. \& Lago, M.S. (1994). Representação da paternidade entre sujeitos das camadas médias urbanas em Florianópolis. [Resumo]. Em Sociedade Brasileira de Psicologia (Org) Resumos de Comunicações Científicas, XXIV Reunião Anual de Psicologia. (p.124). Ribeirão Preto: SBP.

Teles, M. A. A. (1993). Breve história do feminismo no Brasil. São Paulo: Brasiliense.

Trindade, Z.A., Andrade, C.A. \& Souza, J.Q. (1993). Representações sociais masculinas de papéis parentais conforme nível de escolaridade e trabalho da mulher. Em Sociedade Brasileira de Psicologia (Org.), Resumos de Comunicações Científicas, XXIII Reunião Anual de Psicologia (p. 404). Ribeirão Preto: SBP.

Winckler, C.R. (1983). Pornografia e sexualidade no Brasil: da repressão à dessublimação. Porto Alegre: Mercado Aberto.

Velho, G. (1985) A busca de coerência: coexistência e contradições entre códigos em camadas médias urbanas. Em S. Figueira (Org.), Cultura da Psicanálise (pp.169-177) São Paulo: Brasiliense.

\section{Apoio: FAPESP}

